\title{
Re-examining the Spatial Distribution of Fluoride in Groundwater of Sri Lanka: A Field Study at Nochchiyagama, Anuradhapura
}

\author{
A.T. Cooray, T. De Fonseka*, S.P. Deraniyagala \\ Department of Chemistry, University of Sri Jayewardenepura, Sri Lanka \\ *thiwarox@msn.com
}

\begin{abstract}
Fluoride is well known for both beneficial and detrimental effects on human health. Fluoride improves the dental health by preventing cavities. However, excessive amounts of fluoride lead to the development of dental and skeletal fluorosis. There is a narrow range between fluoride intake which is advantageous and those which begin to be damaging. Dental fluorosis caused by fluoride rich drinking water is a common health issue in the dry climate zone of Sri Lanka. The spatial distribution of fluoride in groundwater in Sri Lanka has been extensively studied and several fluoride distribution maps have been published to date. However, careful analysis of these maps reveal that the fluoride distribution presented in some geographical regions does not agree with each other. This study focused on examining the fluoride distribution in Nochchiyagama, Anuradhapura to re-evaluate its fluoride distribution. During the study, approximately 200 water samples were collected from dug and tube wells, water reservoirs and canals. Fluoride concentration of the samples was determined by the fluoride selective electrode method. Other physico-chemical properties of water such as $\mathrm{pH}$, conductivity, hardness etc. were determined by internationally accepted standard methods. The average fluoride concentration in Nochchiyagama was $1.1 \pm 0.8 \mathrm{mg}^{\prime} 1(\mathrm{n}=202)$ in the range 0.29 to $5.52 \mathrm{mg} / \mathrm{l}$; however, many of the published maps state the fluoride distribution in the Nochchiyagamaarea as 0.5 to $1.0 \mathrm{mg} / \mathrm{l}$. A careful examination of the fluoride data reveals two distinct fluoride distribution patterns. The geographical area between the Puttlam-Anuradhapura highway (A12) and the Wilpaththu National Park generally has a higher fluoride content with an average $1.2 \pm 1.0 \mathrm{mg} / \mathrm{l}(\mathrm{n}=103)$ in the range 0.31 to $5.52 \mathrm{mg} / \mathrm{l}$. The area between Puttlam-Anuradhapura highway (A12) and Thabuththegama-Anuradhapura highway (A28) has an average fluoride concentration of $0.9 \pm 0.5 \mathrm{mg} / \mathrm{l}(\mathrm{n}=99)$ in the range 0.29 to $2.53 \mathrm{mg} / \mathrm{l}$. The first geographical area had about eight fluoride hot spots $(<2.5 \mathrm{mg} / \mathrm{l})$ while other region had only two. One of the most visible hydrological differences in these two regions is that the first region solely depends on rainwater for water requirements while the other one has a complex network of irrigational canals distributing water from the Kala Oya irrigational scheme.
\end{abstract}

Keywords: Fluoride distribution, Nochchiyagama

Acknowledgement: Authors acknowledge the financial assistance of University of Sri Jayewardenepura (Research Grant ASP/06/RE/SCI/2013/09) 